Part of Journal of Research of the National Bureau of Standards, Volume 23, August 1939

\title{
PREPARATION OF CRUCIBLES FROM SPECIAL REFRACTORIES BY SLIP-CASTING
}

\author{
By John G. Thompson and Manley W. Mallett
}

\section{ABSTRACT}

The slip-casting process, which is widely used in ceramics, has not been generally applied to the preparation of crucibles from special refractories, which lack the property of plasticity. However, enough plasticity to make slip-casting feasible can be developed in some of the special refractories by fine grinding and treatment with acid. Thin-walled crucibles of alumina, beryllia, zircon, zirconia, and electrically fused thoria were cast from aqueous slips, and bricks $5 \mathrm{~cm}$ thick were made by a modified process. Magnesia crucibles could not be cast from aqueous slips but were formed successfully from a suspension of finely ground magnesia in absolute alcohol.

\section{CONTENTS}

I. Introduction

II. Slip-cast beryllia crucibles _...

III. Slip-castings of zirconia, zircon, alumina, and electrically fused thoria ${ }_{--} 323$

IV. Slip-cast magnesia crucibles

V. Summary_._._.

VI. References

\section{INTRODUCTION}

Researches in refractory materials frequently are necessitated by metallurgical researches at elevated temperatures, particularly when treatment of molten metal of high purity is involved. The material from which crucibles are made must be chemically inert to the molten metal, free from impurities that may be transferred to the metal, and must not melt or soften in use. The containers for this type of research must be of the desired shape, size, and capacity, sufficiently strong and resistant to thermal and mechanical shock, and resistant to the erosive action of the molten metal.

Except for carbon or graphite, which react with many metals at elevated temperatures, refractory materials with melting points above $1,600^{\circ} \mathrm{C}$, and of sufficiently high purity and chemical stability to be suitable for melting high-purity metals, practically are limited to purified oxides (and in some cases silicates), such as those of aluminum, beryllium, calcium, magnesium, thorium, and zirconium. The relative merits of these refractory materials and the factors that determined the selection of one or another in several investigations at the National Bureau of Standards, have been discussed in previous publications $[1,2,3,4] .{ }^{1}$ Crucibles were formed by tamping or pressing the refractory into the desired shape, as described in detail by Swanger and Caldwell [3].

\footnotetext{
${ }^{1}$ Figures in brackets indicate the literature references at the end of this paper.
} 
Crucibles prepared in this manner have been quite satisfactory for small melts of highly purified metals, particularly metals of the platinum group and their alloys. However, in the current study of high-purity iron [4] it became evident that the pressing or tamping procedure was not so satisfactory for the production of larger crucibles for melting 600 to $800 \mathrm{~g}$ of iron. The preparation of these relatively thick-walled crucibles required large amounts of refractory, and their bulk was objectionable in a furnace whose capacity was limited. However, the principal objection to tamped crucibles, for melting high-purity iron in a high-frequency induction furnace, was contamination of the melt by particles detached from the walls of the crucible. Ingots of iron melted and allowed to solidify in tamped crucibles usually had very rough surfaces in which large and small particles of refractory were tightly embedded, and even the apparently clean metal from the interior of the ingots was contaminated to some extent by the refractory, as was shown by the results of spectroscopic examination.

Attention was therefore turned to other methods of preparing crucibles, primarily to obtain more resistant and more nearly perfect inner surfaces. It was found that the process of slip-casting, which is so widely used in the ceramic industry, could be modified to produce high-quality, thin-walled crucibles of the desired type from nonplastic refractory materials.

The process of slip-casting, as applied to the production of clay ware, is simple in principle. The "slip," which is an aqueous suspension of the clay mixture, is poured into a plaster of paris mold where it gradually solidifies by absorption by the plaster of water from the slip. The solidified casting is subsequently removed from the mold and is dried and fired.

Although the slip-casting process for the production of clay ware is simple in principle, its successful application requires control of many variables, which were discussed in detail by Hall [5].

Slip-casting of special refractories differs from that of clay in one important respect, that is, most clays are more or less plastic and selfbonding, whereas the special refractories are nonplastic. This is particularly true of calcined refractories; and calcination, to preshrink the material prior to forming it into crucibles for use at high temperatures, is quite necessary to minimize destructive shrinkage of the completed crucible when it is fired. In earlier work on the slipcasting of special refractories at this Bureau [1], small amounts of clay or organic compounds were incorporated in the slip to serve as a bond for the nonplastic refractory, but this practice was not entirely satisfactory because the added material lowered the softening temperature of the refractory, or because it contaminated the highpurity metal in subsequent melting operations, or both. However, Ruff [6] showed that the addition of a plastic material was not always necessary, and that treatment of finely ground refractory oxides with acids or alkalies developed plasticity in the otherwise nonplastic materials. Ruff worked with zirconia, alumina, and silica. Our study of slip-casting started with beryllia, which was the refractory selected for the work with high-purity iron, and was extended to include other refractories. 


\section{SLIP-CAST BERYLLIA CRUCIBLES}

The beryllia used in this work was a commercial product of "chemically pure" grade prepared by calcination of beryllium sulphate. The beryllia was heated to about $1,800^{\circ} \mathrm{C}$ in graphite shells in an evacuated Arsem furnace to convert the finely granulated powder to a loosely coherent cake whose volume was approximately 85 percent of that of the powder. The cake, after being crushed to pass through a No. 10 sieve, was ground in a steel ball mill which was two-thirds filled with a mixture of equal volumes of beryllia and steel balls 1 inch in diameter. The mill rotated at about $70 \mathrm{rpm}$. Satisfactory grinding was determined by the behavior of the material in casting operations rather than by direct determinations of the particle sizes. Insufficient grinding was indicated by the presence of coarse particles which settled rapidly from the casting slip, and by a rough, sandy surface and low strength in the castings. Over-ground material yielded castings that formed very slowly and that cracked in drying. It was found that 8 hours' grinding yielded satisfactory material, and this grinding period was used in all of the work with beryllia. Wet grinding appeared to be somewhat faster than dry grinding, but the latter was generally used in our work because of greater convenience in cleaning the dry mill and in storing the dry powder.

Enough of the ground material to produce 1 day's castings was transferred to a large bottle together with about twice its volume of diluted hydrochloric acid $(1+9)$, and the mixture was thoroughly shaken. Reaction of the acid with fine particles of iron from the ball mill kept the mixture stirred at first; but when the mixture stood for 2 or 3 hours, the beryllia settled out and most of the discolored acid could be removed by siphoning. Fresh acid was added and was mixed with the beryllia by shaking. After a suitable period of settling, the spent acid was replaced by a third portion of fresh acid, the mixture was shaken and then allowed to stand overnight, after which the supernatant acid was siphoned off as completely as possible.

This treatment was sufficient to impart the necessary plasticity to the beryllia and to remove the iron which was introduced during grinding. Good crucibles could be prepared from a suspension of the acid-washed beryllia in diluted hydrochloric acid, but equally good castings could be obtained from less-acid slips which were less destructive to the plaster molds. Consequently, after siphoning off the final portion of diluted acid, the beryllia was washed three or four times with water. The beryllia settled more slowly with each successive washing until, after the final addition of fresh water, the supernatant liquid remained cloudy for several hours. After the mixture had stood overnight, the water was siphoned off as completely as possible. This left the beryllia in the form of a firm, damp cake which could be transformed, by stirring or shaking, into a thinly fluid slip. Too much dilution caused rapid settling of the slip, whereas an insufficient amount of water produced a viscous slip from which it was difficult to eliminate air bubbles. If the consistency of the slip was that of rather thin cream and, further, if the entrapped air bubbles rose rapidly and freely to the surface before appreciable settling of the beryllia occurred, the slip was ready for casting. A few observations of the volumes of diluted acid and water that were added to and siphoned from the beryllia showed that satisfactory slips usually contained between 60 and 70 percent by weight of solid matter. 
To form a crucible, the slip was poured into the plaster mold ${ }^{2}$ rapidly but without splashing or entrapping air. The plaster immediately began to absorb water from the slip, and a film of solidified material formed on the walls. The liquid level within the mold was maintained by additions of slip until the film of solidified material reached the desired thickness. The mold was then inverted and the residual liquid slip was poured out. The time required to form a crucible with a wall thickness of 2 or $3 \mathrm{~mm}$ usually was about 1 minute, but this varied with the consistency and acidity of the slip and with the condition of the plaster mold. If the plaster was too wet, the crucible formed slowly, hardened slowly, and adhered to the mold. Similar difficulties were encountered in casting an old slip in which the beryllia had been wet continuously with acid or water for more than a week. If the plaster was too dry, the crucible formed so rapidly that the process was hard to control, and the crucible usually collapsed and was poured out of the mold along with the excess of liquid slip. When the proper condition of a plaster mold was once attained, it could be maintained by making only one or two castings per day, then inverting the empty mold and allowing it to dry overnight. With this schedule 25 or more crucibles have been cast in a single mold, although the later crucibles in the sequence formed slowly because of slow absorption by the old plaster, and these crucibles were removed with difficulty from the mold because rough spots in the plaster served to anchor the crucible to the mold. Some molds reached the limit of their usefulness when they began to produce bubbles of gas, either because of some chemical reaction, such as that of hydrochloric acid with calcium carbonate, or because there were channels in the plaster from which the air was displaced by the water absorbed during a casting. Such gas bubbles were retained in the semisolidified slip and produced imperfect crucibles.

If the crucible formed properly, it remained in the mold when the excess of liquid slip was poured out; but it was too soft and plastic at this stage to support its own weight or to be removed from the mold. The crucible, therefore, was allowed to remain in the mold for further drying by absorption of water by the plaster and by evaporation from the inner surface of the casting. After about 2 hours the inner surface was dry and firm to the touch and shrinkage cracks began to appear at the junction of the top of the crucible and the wall of the mold. The casting then could be removed from the mold, particularly if the mold was gently tapped and rolled before it was inverted. The crucibles at this stage were somewhat plastic but were strong enough to be removed from the mold without collapsing. They were air-dried for about 24 hours and then were heated slowly for another 24 hours during which the temperature rose to about $180^{\circ}$ C. Drying in this manner did not appreciably affect the dimensions of the crucible, but subsequent firing to $1,750^{\circ}$ or $1,800^{\circ} \mathrm{C}$ was accompanied by a linear shrinkage of about 10 percent. The density and shrinkage of the crucible increased, and the porosity decreased,

2 The molds in which the castings were made were prepared as follows: Plaster of Paris of a grade suitable for making molds was stirred into water in the approximate proportions of 4 parts by weight of plaster to 3 parts of water. The thoroughly mixed mass was gently stirred and jarred to eliminate air bubbles and was then poured into a cardboard cylinder in which was suspended a slightly tapered brass mandrel that was covered with a thin film of lard oil. The mandrel and cylinder were arranged to produce a plaster casting with uniform thickness (about $3 \mathrm{~cm}$ ) of walls and bottom. The inner surface of a satisfactory plaster casting, after the mandrel was withdrawn, was smooth and free from gas pockets or mechanical defects. The cardboard shell was stripped from the solidified plaster, and after the mold had been allowed to air-dry for several days at room temperature, it was ready for use. 


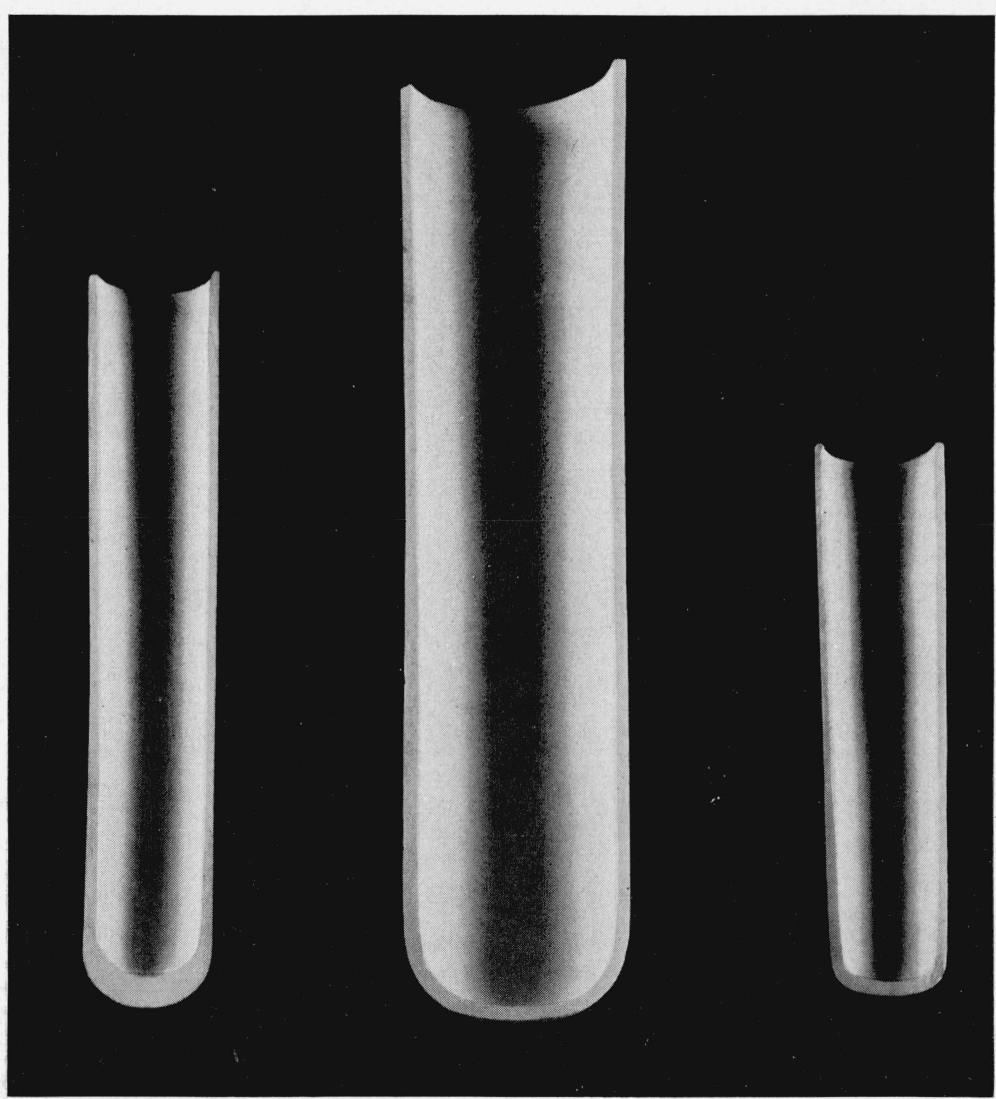

FIGURE 1.-Sections of slip-cast crucibles, exhibiting the smooth inner surfaces and thin uniform walls. 


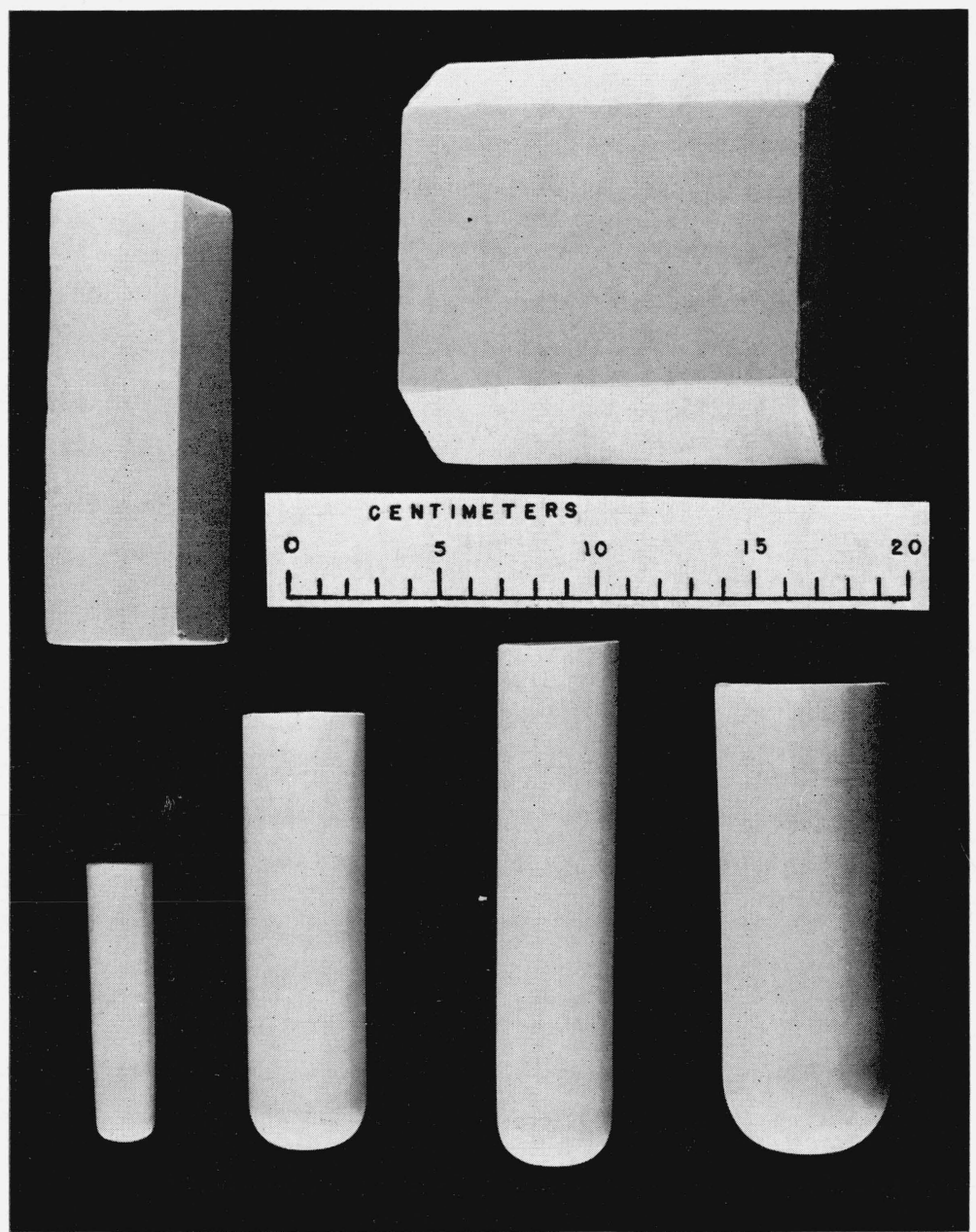

Figure 2.-Specimens of crucibles and bricks prepared by slip-casting. The small crucible weighed 50 grams; the circle brick weighed 1,700 grams. 
with increasing temperature of firing; but a maximum temperature of $1,750^{\circ}$ or $1,800^{\circ} \mathrm{C}$ was used in our work, primarily to provide a safe margin for subsequent use of the crucibles at about $1,600^{\circ} \mathrm{C}$ rather than to produce a desired degree of porosity or density. Breakage of crucibles during firing was negligible when about 3 hours was required to reach the maximum temperature and this temperature was maintained for about 1 hour. After firing, the crucibles were white, hard, strong, and resistant to shock, with a structure similar to that of porcelain. If a suspended crucible was struck lightly, it responded with a clear, bell-like ring.

The split halves of the 3 crucibles that are shown in figure 1 illustrate the excellent inner surfaces and uniform walls that were attained in slip-cast crucibles. The largest of the 3 crucibles was $16 \mathrm{~cm}$ long with a capacity of $140 \mathrm{~cm}^{3}$, the smallest was $9 \mathrm{~cm}$ long with a capacity of $20 \mathrm{~cm} .^{3}$ The wall thickness of each of the three was $2.5 \mathrm{~mm}$. In most of the crucibles the thickness of the bottom was the same as that of the walls; but the crucible shown at the left in figure 1 had a thick bottom, presumably because the bottom of the mold was dry and absorbed water from the slip faster than did the side walls. The largest slip-castings of beryllia that were attempted were crucibles $5 \mathrm{~cm}$ in inside diameter, $15 \mathrm{~cm}$ long, with walls $4 \mathrm{~mm}$ thick, and with a capacity of about $300 \mathrm{~cm}^{3}$. One of these shells which were used to support smaller crucibles in melting operations is included in figure 2.

\section{SLIP-CASTINGS OF ZIRCONIA, ZIRCON, ALUMINA, AND ELECTRICALLY FUSED THORIA}

The success achieved in slip-casting beryllia led to experimentation with other refractories. No particular difficulty was encountered in slip-casting zirconia, zircon, or electrically fused thoria of the grades which had been previously used for the production of tamped or pressed crucibles [3]. However, some details of the procedure, for example, the time of grinding and the amount of water to make a suitable casting slip, necessarily were varied for different refractories. Electrically fused thoria required the longest grinding. Although crucibles made from this material did not shrink appreciably on drying in the mold, they were strong and heavy enough to permit their removal. The shrinkage of thoria crucibles on firing to $1,750^{\circ}$ or $1,800^{\circ} \mathrm{C}$ was very low.

Alumina of satisfactory purity for use as a high-temperature refractory is a relatively new product. The best alumina that was previously available in this country was the purified oxide that was used for the production of metallic aluminum. The principal impurities in this material were sodium salts, equivalent to a content of about 0.5 percent of $\mathrm{Na}_{2} \mathrm{O}$, which lowered the sintering temperature of the alumina and increased its susceptibility to contamination by carbon. However, a special grade of purified alumina, "Grade A-10," is now available, the $\mathrm{Na}_{2} \mathrm{O}$ content of which is about 0.1 percent and the other impurities are lesser amounts of the oxides of iron, silicon, and titanium.

The procedure employed in slip-casting crucibles of both grades of alumina was practically the same as was used for beryllia. The alumina as received had been calcined and was finely granulated, about 35 percent being retained on a No. 200 sieve. This material 162919-39-9 
was ground in a steel ball mill for 8 hours, treated with hydrochloric acid at room temperature for 24 hours, and washed with water for 24 hours. Crucibles made from alumina, which contained 0.5 percent of $\mathrm{Na}_{2} \mathrm{O}$, were sintered more than those made from $\mathrm{A}-10$ alumina and fired at the same temperature. The increased sintering presumably resulted from the presence of sodium salts in spite of the treatment of the finely ground alumina with hydrochloric acid. Shrinkage of the alumina crucibles on firing to $1,750^{\circ} \mathrm{C}$ was about 15 percent, somewhat more than that of the beryllia; but the latter was calcined to $1,800^{\circ} \mathrm{C}$, whereas the alumina was calcined at about $1,500^{\circ} \mathrm{C}$.

The preparation of slip-cast crucibles of purified alumina, for use at high temperatures, has received more attention abroad than it has in this country and has been described in several papers in English journals $[7,8,9]$. Most of these procedures are more complicated and less convenient than ours. In some instances grinding for 100 hours was required; in several instances the treatment of the finely ground material with acid was done at temperatures that approached the boiling point of the mixture, or the slip was heated before it was cast. Our experiments indicated that satisfactory results were obtained with less than 10 hours' grinding and, further, that the entire process could be carried out at room temperature. These variations in detail are of minor importance, and all processes for slip-casting alumina are based on Ruff's discovery [6] that plasticity could be developed in nonplastic refractories by fine grinding and treatment with acid.

Brick for the construction of a small high-temperature furnace also were made from A-10 alumina by a modified slip-casting procedure. The alumina, not ground, did not develop a satisfactory bonding power when it was treated with diluted hydrochloric acid and washed with water. Brick formed from this material could be removed from the mold and were somewhat plastic while they were damp but lost their cohesion in drying and were converted to friable, sandy masses when they were heated to $150^{\circ} \mathrm{C}$. On the other hand, alumina that had been ground for 8 or 10 hours in the ball mill and then treated with acid and water could be formed into brick that did not disintegrate when they were dried, but which, unfortunately, cracked badly. However, neither of these difficulties was encountered when a mixture of equal weights of unground alumina and of material that had been ground for 10 hours was used.

The procedure for casting the brick that were $5 \mathrm{~cm}$ thick differed in several respects from that used for the thin-walled crucibles, particularly in the thickness of the slip and in the type of mold. To form one brick of each of the two sizes illustrated in figure $2,1,300 \mathrm{~g}$ of alumina that had been ground for 10 hours was mixed with $1,100 \mathrm{~g}$ of unground material. The mixture was treated with diluted hydrochloric acid for 24 hours and then was washed with water. After the mixture had stood overnight in a large evaporating dish, the water was siphoned off as completely as possible, and $200 \mathrm{~g}$ of dry unground $\mathrm{Al}_{2} \mathrm{O}_{3}$ was stirred into the mixture to form a pasty slip and to bring the composition to equal weights of ground and unground alumina. These slips contained 75 percent or more of solid matter.

Molds for the brick were without top or bottom and were made of wood. The surfaces of the mold that would be in contact with the slip were wrapped with strips of filter paper and the mold was then 


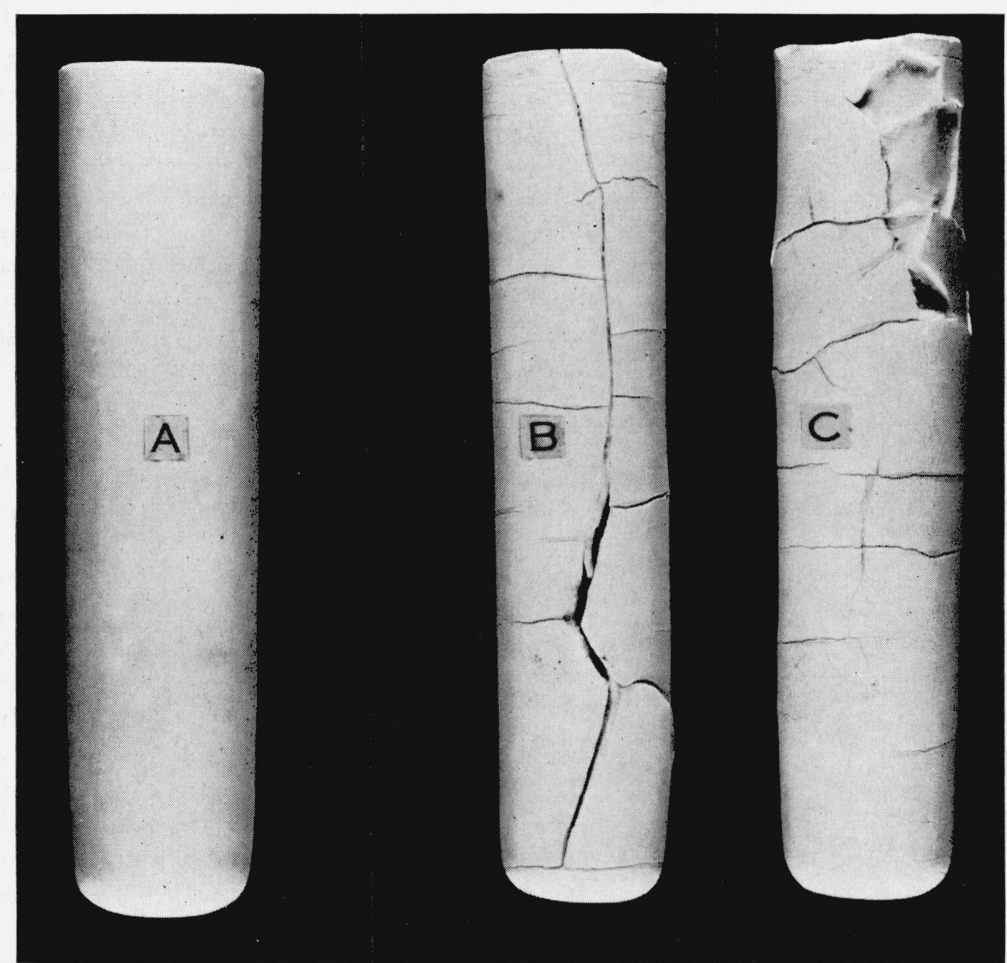

Figure 3.-Slip-cast magnesia crucibles.

Satisfactory crucibles, such as $A$ were obtained from slips made with absolute alcohol. Crucibles $B$ and $C$ were cast from aqueous slips and cracked during firing. 
placed on a sheet of filter paper which in turn rested on a porous plate in a large funnel. The pasty slip was transferred to the mold by means of a large spatula or scoop, and each addition was puddled to fill the corners of the mold to insure complete mixing and to facilitate removal of air bubbles. After the mold was full, small additions of slip were made from time to time to compensate for the shrinkage, which was completed in about 2 hours. The casting was allowed to remain undisturbed in the mold for 2 or 3 hours more, the mold was then removed, the filter paper was stripped from the casting, and the latter was air dried for 36 hours. It was then baked at $150^{\circ} \mathrm{C}$ in an electric oven and subsequently was fired to about $1,425^{\circ} \mathrm{C}$ in one of the Bureau's kilns. ${ }^{3}$ Some of the brick were fired to $900^{\circ} \mathrm{C}$ in an electric muffle, prior to firing to $1,425^{\circ} \mathrm{C}$, but this intermediate firing was not an improvement over direct firing from the baked condition. In fact some of the brick were rather fragile after firing to $900^{\circ} \mathrm{C}$, whereas there were no failures and no serious checks or cracks during the firing to $1,425^{\circ} \mathrm{C}$. After baking at $150^{\circ} \mathrm{C}$, the loss in weight of a $1,700-\mathrm{g}$ brick on firing to $1,425^{\circ} \mathrm{C}$ did not exceed 5 or $10 \mathrm{~g}$, and the linear shrinkage was only about 1 percent. Examples of two types of brick fired to $1,425^{\circ} \mathrm{C}$ are shown in figure 2 . The circle brick were $5 \mathrm{~cm}$ thick, 14 by $9 \mathrm{~cm}$ at one face, and 14 by 14 $\mathrm{cm}$ at the other. The soaps were $5 \mathrm{~cm}$ square, $15 \mathrm{~cm}$ long, and weighed about $800 \mathrm{~g}$ each. The slip-cast articles shown in figure 2 vary in weight from $1,700 \mathrm{~g}$ for the circle brick to less than $50 \mathrm{~g}$ for the small crucible.

\section{SLIP-CAST MAGNESIA CRUCIBLES}

The slip-casting of calcined ground magnesia presented unusual problems because of the tendency of this material to react with acids and even with water. Treatment of the ground material with diluted hydrochloric acid dissolved some of the magnesia and converted the rest to a hard, nonplastic mass. Various proportions of alcohol were added to the diluted hydrochloric acid in the hope that the reaction with the magnesia could be inhibited, but without success. It was concluded that the removal of iron, from grinding in the steel ball mill, was not practicable by treatment with diluted acid. Furthermore, the treatment with acid was not needed to develop plasticity in the magnesia; this material developed excessive plasticity from treatment with water. A few successful castings of magnesia were made from water slips, but many difficulties were encountered. The magnesia slip was sticky and rubbery as compared to slips of the other refractories, and the castings were soft and weak and stuck tightly to the mold. Of the few good castings that were successfully removed from the mold, none was satisfactorily dried and fired. All developed cracks and checks, as did the two crucibles shown at the right in figure 3. However, crucibles which cast well and which could be dried and fired without breakage, as exemplified by the crucible at the left of figure 3 , finally were obtained through the use of a nonaqueous liquid to form the slip.

Magnesia crucibles were slip-cast successfully as follows: Magnesia that had been previously calcined to about $1,800^{\circ} \mathrm{C}$ was ground in a steel ball mill. Enough of the ground magnesia to make a 1

3 The authors are indebted to R. A. Heindl and his associates in the Refractories Section of the Bureau for the use of the kiln and for information about ceramic slip-casting. 
day's supply of castings was covered with an excess of absolute alcohol, and the mixture was shaken vigorously several times and then allowed to settle overnight. In the morning most of the supernatant liquid was siphoned off until only enough remained to convert the cake of magnesia into a fluid slip of the desired consistency when the mixture was shaken.

To obtain a stable suspension in alcohol, that is, one which did not settle rapidly, required longer grinding than was necessary for aqueous slips. Magnesia ground in the ball mill for 17 hours made a satisfactory slip with absolute alcohol. The casting slips contained 80 to 85 percent solid matter and were somewhat more viscous than the aqueous slips. It should be emphasized that the medium for successful slip-casting of magnesia was absolute alcohol. Slips made with 95-percent alcohol were no better than slips made with water alone.

Castings of magnesia formed rather slowly, dried rather slowly, and tended to stick to the mold. However, the green crucibles appeared to be quite tough and able to withstand the rather severe jolting of the mold that was usually necessary to free the castings. No difficulty was encountered in drying and firing the crucibles, although the magnesia, perhaps because it contained impurities that were removed from the other refractories by the treatment with acid, was not quite as refractory as the beryllia or purified alumina. When fired to $1,750^{\circ}$ or $1,800^{\circ} \mathrm{C}$ the magnesia crucibles became somewhat vitrified and tended to warp out of shape. At $1,650^{\circ}$ or $1,700^{\circ} \mathrm{C}$ they kept their shape but tended to vitrify more than did the other refractories at temperatures $100^{\circ} \mathrm{C}$ higher.

Absolute alcohol was the only successful vehicle for slip-casting magnesia that was found in our experiments, but equally good success perhaps could be attained with other nonaqueous, nonhydrating media.

\section{SUMMARY}

1. Beryllia crucibles with uniform thin walls, smooth inner surfaces, and with capacities up to $300 \mathrm{~cm}^{3}$ were prepared by a slip-casting process.

2. The necessary plasticity for slip casting was developed in calcined, finely ground beryllia by treatment with diluted hydrochloric acid at room temperature.

3. Good castings were obtained from suspensions of the acidtreated beryllia in diluted hydrochloric acid, but equally good castings and longer life of the plaster molds were obtained when the diluted acid of the casting slip was replaced with water.

4. The slip-casting process that was developed for beryllia was also used for the preparation of crucibles of alumina, thoria, zircon, and zirconia.

5. Slip-cast crucibles had wall thicknesses of about $3 \mathrm{~mm}$, but brick $5 \mathrm{~cm}$ in thickness were prepared by a modification of the slip-casting process.

6. Crucibles of magnesia, which could not be cast from aqueous slips, were cast from suspensions of magnesia in absolute alcohol. 


\section{REFERENCES}

[1] L. Jordan, A. A. Peterson, and L. H. Phelps, Trans. Am. Electrochem. Soc. 50, $155(1926)$.

[2] L. Jordan and W. H. Swanger, BS J. Research 5, 1291 (1930) RP257.

[3] W. H. Swanger and F. R. Caldwell, BS J. Research 6, 1131 (1931) RP327.

[4] J. G. Thompson and H. E. Cleaves, J. Research NBS 23, 163 (1939) RP1226.

[5] F. P. Hall, J. Am. Ceram. Soc. 13, 751 (1930).

[6] O. Ruff, Z. anorg. allgem. Chem. 133, 187, 193, 220 (1924); 173, 14 (1928).

[7] D. Turner, Trans. Faraday Soc. 2\%, 112 (1931); Trans. Ceram. Soc. 33, 33 (1933-34).

[8] J. H. Partridge and J. R. Lait, J. Soc. Glass Tech. 20, 200 (1936).

[9] V. H. Stott, Trans. Ceram Soc. 3y, 346 (1938).

Washington, June 13, 1939. 